\title{
Systemic Signaling Under Water Deficit Condition and Its Exploitation in Water Saving Agriculture
}

\author{
Bingbing Li and Wensuo Jia \\ College of Agronomy and Biotechnology, \\ China Agricultural University, Beijing \\ China
}

\section{Introduction}

To live and thrive in an ever changing environment, a living organism must be capable of sensing the environmental stimuli and making corresponding adaptive responses. This "stimulus-response" process is mediated by a series of signaling events. It appears that the more advanced the organism is, the more positive and quicker the responses display. This can be best demonstrated in animals where the nerve-mediated signaling enable animal to react swiftly and purposefully, thus preserving them from possible harms. The nervemediated signaling is characterized by a pattern of long-distance signaling, i.e., when one part is stimulated another distinct part of the body may take corresponding actions. Systematic signaling can be interpreted as a pattern of "stimulus-response" that when local part is stimulated the whole body may take corresponding actions. Clearly, long-distance signaling is the basis of the systemic signaling and embodies a kind of advanced responding behavior to an ever changing environment. While the systemic signaling has been well known for its crucial roles of in animals, it has been largely overlooked in plants owing to the inability of plants to move. In recent years, with a rapid progress in molecular biology, the molecular mechanisms for stress-resistance in plants have attracted considerable attentions. Studies on the molecular basis of stress tolerance have revealed that in response to environmental stresses expressions of numerous genes associated with stress tolerances can be regulated, indicating that plant cells are indeed able to sense and respond to environmental stresses. Like animals, the growth and development of advanced plants depends a cooperative regulation of different tissues and organs, therefore, plants should have evolved the capability to sense and respond to various stress stimuli through the systemic signaling. Nevertheless, while particular interests and attentions have been paid on the cellular signaling transduction, knowledge about the roles of the systemic signaling in plant adaptation responses is relatively scarce.

\section{The root to shoot signaling plays critical roles in plant adaptive responses to drought stress}

It has been traditionally thought that soil drying will limit water uptake by roots and this will inevitably result in the declination of leaf water status. However, much work suggests 
that in many cases the leaf water status is not closely correlated with the water availability of the root system. This has raised a question of whether the leaf water status may be regulated by an unknown mechanism other than by the hydraulic control, and it has been increasingly suggested that this unknown mechanism is the root to shoot chemical signaling.

Indirect evidence supporting the root to shoot signaling came from the observations on the disconnected relationship between the leaf and soil water status and that between leaf physiology and leaf water potential. It has been generally accepted that leaf physiology, such as leaf growth and stomatal movement, is predominantly regulated by the leaf water potential, which is again directly regulated by the soil water status. However, for many years much data suggest that leaf growth and stomatal movement may be regulated even when no perceptible changes in the leaf water potential occur, and also, the changes in leaf water potential may not be closely linked to to that in the soil water status. In contrast, it is often observed that variation in leaf conductance and growth may be linked more closely to changes in soil water status than to changes in leaf water status. This appears to suggest that leaf stomatal movement or growth may be regulated by a signal sourced from roots.

Direct evidences came from studies where the experiments were subtly designed so that the coupling relationship between the leaf and soil water status was broken. A classic experiment to do this is the split-root experiments. A well demonstrated example is splitroot experiment with clonal apple trees (Gowing, 1990 ), where the root systems of individual plants were split into approximately two half parts, with each part contained in a individual container. With-holding water from half of the root system reduced the rate of leaf growth while no significant reduction in the leaf water potential could be observed. Further more, rewatering restored the rates of leaf growth to that of the well watered control plants. Interestingly, excising the roots in dry soil also restored the rates of leaf growth, which strongly suggested that the reduced rate of leaf growth was a result of inhibition by the roots in drying soil. Numerous studies on split-root have provided evidences supporting the existence of root to shoot signaling in different plant species. Besides the spit-root experiment, strong evidences also came from the soil pressure chamber experiment, where the coupling relationship between the reduction of leaf water status and soil drying can be destructed by supplying a pressure on the roots. In this way, a reduction in the leaf water potential of the unwatered plants can be avoided while the soil was allowed to dry, but the roots of these plants were still in contact with drying soil. In an investigation on wheat and sunflower plants, Passioura and colleagues (Passioura and Munns, 1984 ) found that soil drying could cause a significant reduction in leaf conductance of pressurized plants while it had no effect leaf water potential, suggesting the existence of root to shoot signaling. Collectively, in the past may years with different approaches and plant species it has been well established that root to shoot signaling plays critical roles in the regulation of shoot responses to soil drying.

\section{The nature of signals mediating root to shoot signaling}

\subsection{ABA signaling}

\subsubsection{Evidences for ABA signaling}

It is well known that soil drying will cause a declination in the root water status and this will eventually cause a declination in the leaf water status, hence, the leaf water status has been commonly used as an indicator of the soil water status. Clearly, the nexus between leaf 
and soil water status is coupled directly through the variations of the water potential along vascular system. Therefore, a variation in the hydraulic nexus between leaf and root can be the best signal (hydraulic signal) to mediate the responses of the leaf physiology to the water deficit of roots. However, for the root to shoot signaling concerned here particularly refers to the case that is before the hydraulic signaling occurring, or the case in which the leaf growth or stomatal movement is not coupled with the variation in the leaf water potential. The only logical hypothesis is that such a root to shoot signaling is mediated by some chemical substances. It is well known that the transportation of materials from root to shoot is achieved though transpiration stream, therefore, it is reasonable to think that the chemical signals mediating the root to shoot signaling should be contained in the transpiration stream. A wide analysis of the effect of soil drying on the xylem sap compositions indicated that concentrations of most components decline as the soil around the roots is allowed to dry except for the plant hormone abscisic acid (ABA). Mild soil drying will cause a significant increase in xylem sap ABA concentration (Neales, 1989 ). It has long been known that ABA can be synthesized in nearly all plant species and tissues. Given the potential roles in root to shoot signaling, the regulation of ABA synthesis in roots has attracted particular attentions (Cornish and Zeevaart,1985; Hubic et al., 1986; Lachno and Baker, 1986; Robertson, et al., 1985; Walton et al., 1976 ). Dehydration of detached roots is able to induce ABA accumulation (Neales, 1989 ) and comprehensive analysis of ABA contents of roots in different parts of the soil profile shows a close relationship between the ABA content and water status in the root profile (Atkinson, et al., 1989; Davies 1987). These evidences suggest that ABA may be a candidate signal mediating the root to shoot signaling.

More strong evidences supporting ABA to be a root to shoot signal is the close relationship between a variation in xylem ABA concentration and the leaf physiology. For example, it was reported that the ABA concentration in xylem sap from well-watered maize and sunflower plants is only around $10 \mathrm{nM}$, and this concentration can rise by one or two orders of magnitude (Schurr and Gollan, 1990; Zhang and Davies, 1989; 1990 ) as a function of mild soil drying. Besides maize and sunflower, mild soil drying can induce a substantial increase in xylem ABA concentration in many other plant species (Hartung and Radin, 1989; Munns and King,1988 ). Many studies demonstrate that xylem ABA concentration may be a more closely related to stomatal movement than either root ABA or leaf ABA is. Conclusive evinces for the ABA signaling came from bioassay experiments. No matter what ways for ABA supplying, the ABA treatment is able to induce stomatal closure (Zhang and Davies, 1989; 1990). More importantly, feeding xylem sap collected from unwatered maize plants caused an inhibition of transpiration, and removing the ABA from xylem sap by passing through an immunoaffinity column composed of ABA antibodies was able to relieve the antitranspirant activity (Ogunkanmi et al., 1973), strongly indicating that ABA can be a root to shoot signal regulating stomatal movement.

\subsubsection{Arguments about ABA signaling}

It is well known that leaf cells contain a lot of ABA. If root-sourced ABA can be a root to shoot signal mediating the regulation of stomatal movement or leaf growth, how is the ABA synthesized in leaf cells distinguished from the root-sourced ABA? This is actually not a problem because ABA in plant tissues or cells is normally sequestered within some specific spaces as a function of the effect of anion trap (Cowan et al, 1982; Hartung, 1990), e.g. in leaf cells ABA is mainly sequestered within chloroplast. Owing to this sequestration, ABA is not 
able to reach its action sites and therefore not able to play corresponding functions. Carrying by xylem stream, root-sourced ABA is believed to pass through the apoplastic spaces in leaves, where ABA may be able to directly interact with its receptor therefore effectively regulating stomatal movement or leaf growth.

Although it has been well established that root-sourced ABA is capable of regulating stomatal movement, it is not clear how stomatal movement respond to this ABA signal. Xylem ABA concentration, ABA flux entering leaves and the accumulated amount of ABA (mass of $\mathrm{ABA}$ ) within the leaves are three parameters closely related to each other. All these parameters can be changed as a function of soil drying, and so, all of them may become a factor to regulate stomatal movement. It is estimated that the accumulated mass of ABA within an individual leaves per day may be over than the amount of leaf ABA even under the well watered condition. Supposing stomatal movement is capable of responding to the accumulated mass of ABA, such a large amount of ABA accumulated per day would expect to completely inhibit stomatal opening even when plants are well watered. As for the ABA flux, supposing it can be a stomatal responding factor, the root-sourced ABA would also be expected to affect stomatal movement under the well watered condition because a change in ABA flux normally occurs owing to a timely variation in the plant transpiration. There is evidence that stomatal movement may be able to respond to ABA flux and the amount of ABA, but many studies suggest that stomatal movement can only respond to xylem $A B A$ concentration other than the ABA flux or mass. Whatever, substantial studies have suggested that xylem ABA concentration is a predominant factor regulating stomatal movement or other leaf behaviors. With xylem ABA concentration being a major responding factor of stomatal movement, the root sourced ABA can be well as a signal mediating the root to shoot signaling under the water deficit condition, whereas it will not perturb the normal stomatal movement under the non-stressed condition.

\section{$3.2 \mathrm{pH}$ signaling}

As mentioned above, ABA is not evenly distributed but sequestered in plant cells. The sequestration of $\mathrm{ABA}$ is a result of an uneven distribution of $\mathrm{pH}$ within plant cells, i.e. the distribution of ABA in plant cells was pH-dependent (Kaiser and Hartung 1981; Hartung et al. 1988; Hartung and Radin 1989). Based on the determination of ABA uptake in response to $\mathrm{pH}$ in isolated cells or tissues, Hartung's group generated a mathematic model, in which it was predicted that an increase as detected in vivo in response to drought would be enough to induce stomatal closure (Slovik and Hartung 1992a, 1992b). Because of this, it can be hypothesized that $\mathrm{pH}$ may be able to act as a signal if the cellular $\mathrm{pH}$ can be affected by soil drying. A few early works found that drought might indeed be able to trigger a $\mathrm{pH}$ change in different plant species. For example, Hartung and Radin (1989) observed that in response to drought stress the $\mathrm{pH}$ of xylem sap from Phaseolus coccineus roots increased from 6.3 to 7.2; and Gollan et al. (1992) found that in sunflower plants the $\mathrm{pH}$ of xylem sap from shoot increased from a range between 5.8 and 6.6 in well watered plants to 7.0 in the droughtaffected plants. In the Commelina communis plant, it was reported that in response to soil drying, the $\mathrm{pH}$ of xylem sap raised from 6.1 to 6.7, and when artificial xylem sap buffered to different $\mathrm{pH}$ was fed to detached leaves of Commelina communis, and it was found that an increase in $\mathrm{pH}$ from 6.0 to 7.0 caused a reduction of transpiration rate by about $50 \%$ in the presence of low concentrations of ABA. This indicated that a change in xylem $\mathrm{pH}$ may be able to act as a signal mediating the root shoot signaling (Wilkinson and Davies, 1997). The 
stomatal movement in relation to the $\mathrm{pH}$ functioning is complex. $\mathrm{pH}$ may be able to act as a signal to mediate the root to shoot signaling and it may also function but not as a signal to modulate the ABA signaling. The mechanisms for theses two processes are different, and more detailed description will be given in the corresponding parts below.

\subsection{Other signals}

While many studies have suggested that an increase in xylem ABA concentration may be able to mediate root to shoot signaling (Zhang and Davies 1991; Tardieu et al. 1992, Tardieu and Davies 1993; Zhu and Zhang 1997), there are also evidences demonstrating that the root to shoot signaling may be not mediated by the ABA based signaling (Munns et al. 1993; Munns and Cramer 1996; Holbrook et al. 2002). For example, using the graft technique, Holbrook et al. (2002) constructed different kinds of plants grated with the ABA deficient (sitiens) and wild type (flacca) tomato. No matter what method of drying, differences were observed in the changing pattern in the stomatal conductance among the different kinds of grafting combinations, and with this Holbrook et al. (2002) clearly demonstrated that the stomatal closure in response to drought stress does not require ABA production by the root. Besides $\mathrm{ABA}$ and $\mathrm{pH}$, there are possibly some other signals that may be involved in the root to shoot signaling. Ethylene, cytokinin and some biologically active substance may be candidate signals in some cases, but the information about this is much less. Given that $\mathrm{pH}$ can be affected by many factors, it is likely that some $\mathrm{pH}$-regulatory factors may be possibly involved in the root to shoot signaling. For example, it was reported that strong ion differences-SID may be able to alkalize the apoplastic fluid hence serving as a signal to mediate the root to shoot signaling (Hartung and Radin, 1989; Schurr and Gollan, 1990). More detailed information about this will be given in the related sections below.

\section{Modulation of the chemical signaling}

While chemical signaling has been widely accepted to mediate stomatal responses to soil dying, it should be noted that the root to shoot signaling is not just a simple matter of the ABA transmission from root to shoot. A major issue about it is the great variation in the apparent sensitivity of leaf conductance to the root signals. For examples, in some plants chemical signaling may account for a decrease in stomatal conductance by more than $50 \%$ (Zhang and Davies 1989, 1990) or even more than 70\% (Khalil and Grace, 1993), but in some other plants it can only account by less than 20\% (Gollan et al., 1986; Auge et al., 1995; Yao et al., 2001). Theoretically, this can be explained by two major reasons. One is that soil drying is not able to induce significant accumulation of ABA in the roots and another is that stomatal movement is able to sensitively respond to the root-sourced ABA. It appears that soil drying is capable of giving rise to a significant accumulation of ABA in nearly all plants, so it is more likely that the great variation in the regulation of stomatal movement by root signals is a result of the variation of the stomatal sensitivity to the root-sourced ABA.

It is well known that the functioning of ABA depends on a direct interaction of $A B A$ molecule with its receptor. This means that the capability of the root ABA signal to regulate stomatal movement should be determined by both the guard cell itself (i.e. the activity of ABA receptor) and the intensity of the ABA signal in the guard cell. Theoretically, the root to shoot ABA signaling can be divided into three major phases: one is the accumulation and loading of ABA into xylem vessels in the root system, the second is the long-distance 
transmission of the ABA carried by transpiration stream from root to shoot and the third is the unloading and loading of the ABA from xylem vessels and to guard cells. Intensity modification of the ABA signal may occur in each phase above. It has been increasingly suggested that intensity of the ABA signal can be modified by many factors, and these modifications may have important effects on the stomatal sensitivity to the root-sourced ABA signal (Jiang and Hartung, 2008).

\subsection{Modulation of ABA signaling \\ 4.1.1 Effect of radial transport}

The production of ABA in root cells and its loading into xylem vessels is first step in the long-distance transport of ABA. As mentioned above, xylem ABA concentration is a predominant factor being responded by stomatal movement, and hence, modulation of the xylem ABA concentration is a major concern for the long-distance transport of ABA. It was hypothesized that the stele and cortex possess an equal capacity to synthesize $A B A$, and for a long-distance transport $\mathrm{ABA}$ needs to be radially transported from the cortex to the xylem vessel. Xylem ABA concentration should be determined by the radial transport rate of both $\mathrm{ABA}$ and water, and hence the transpiration-caused changes in the rate of the lateral water flow may affect xylem ABA concentration (Else et al. 1994, 1995; Hartung et al. 2002). One concern is the role of Casparian in the radial transport of ABA in root. It is proposed that Casparian may retard the loading of ABA from cortex into xylem vessel and this may cause a high apoplastic $\mathrm{ABA}$ concentration built up in the cortex, and the high concentration of $\mathrm{ABA}$ in the cortex may facilitate an ABA efflux from the roots (Hartung et al. 2002). However, it has been increasingly suggested that ABA may be primarily produced in vascular bundle within the stele other than the cortex (Hartung et al. 2002; HB Ren, KF Wei and WS Jia, unpubl. data, 2007), such that the presence of exodermis and endodermis (site of Casparian formation) will largely retard the efflux of $\mathrm{ABA}$ into soil. In addition, the production of $\mathrm{ABA}$ in the vascular bundle will make it easier to for ABA to be loaded into the vascular vessel.

In regard to the long-distance transport of $\mathrm{ABA}$ from the root to the shoot, it seems that much attention should be paid to the lateral inter-transport of ABA between the xylem and stem parenchyma. There is evidence that ABA can laterally transport between xylem vessel and parenchyma cells in the stem (Sauter and Hartung 2002). The rate of ABA lateral transport is dependent on the ABA concentration gradient between xylem and stem parenchyma, thus under soil drying conditions, the ABA transport from xylem to stem parenchyma will be greatly promoted because the xylem ABA concentration is elevated, and this may give rise to losses of ABA from the xylem and decrease the xylem $A B A$ concentration. Logically, this reduction of the xylem ABA concentration would be directly correlated with the stem length. There is plenty of evidence to suggest that herbaceous plant species compared with woody species are less sensitive to the root ABA signal (Saliendra et al. 1995; Fuchs and Livingston 1996; Comstock and Mencuccini 1998; Yao et al. 2001). Schulze (1991) suggested that large woody species may lack a chemical root signal. It is not known whether the stomatal insensitivity in woody plants may be a result of the modulation of xylem ABA concentration by the radial transport of ABA.

\subsubsection{Effect of catabolism}

It is well known that ABA content in plant cells is determined by a dynamic equilibrium between biosynthesis and catabolism (Zeevaart 1980, 1983; Zeevaart and Creelman 1988). It 
has been well established that a 9_cis-epoxycarotenoid dioxygenase (NCED) catalyzed reaction is a rate-limiting step in the $\mathrm{ABA}$ biosynthesis pathway due to the presence of a large pool of ABA precursors upstream from the NCED, and that the activation of NCED is responsible for the dehydration-induced ABA accumulation (Schwartz et al. 1997; Qin amd Zeevaart 1999; Seo and Koshiba 2002). Because dehydration-induced ABA accumulation is triggered by the activation of NCED, it has been commonly thought that the amount of ABA accumulated in the dehydrated cells is determined by ABA biosynthesis.

However, considering of the dynamic equilibrium between biosynthesis and catabolism, the important role of ABA catabolism in the regulation of ABA accumulation should not be over looked. Logically, supposing that ABA catabolism is kept unchanged or becomes lower in the dehydrated than non-dehydrated cells, the accumulated level of ABA would depend on the sustained time of the dehydration. A sustained soil drying would expect to result in an unlimited accumulation of ABA. Clearly, this will not happen in reality. The key point lies in the absolute rate of ABA catabolism and its variation in response to dehydration stress. Using an 18O-labelling method, Creelman et al. (1987) determined the rate of ABA catabolism, and a half-life of $15.5 \mathrm{~h}$ for the ABA catabolism was calculated in Xanthium leaves. Dehydration-triggered ABA accumulation is very fast, i.e. within several hours the ABA accumulation may reach its maximum (Gowing et al. 1993; Jia et al. 1996; Jia and Zhang 1997; Zhang and Jia 1997; Zhang et al. 1997). Compared with this, the half-life of 15.5 $\mathrm{h}$ for the ABA catabolism implies that the rate of ABA catabolism is very low. In contrast to the observation by Creelman et al. (1987), several lines of evidence strongly suggest that the ABA catabolism is actually very fast (i.e. only about $1 \mathrm{~h}$ in many plant species) (Gowing et al. 1993; Jia et al. 1996; Jia and Zhang 1997; Zhang et al. 1997). A study by Ren et al. (2007) suggested that the dynamic process of ABA catabolism exhibited a pattern of exponential decay and dehydration stress had no effect on the catabolic half-life in maize. This means that the absolute rate of ABA catabolism (i.e. amount of ABA catabolized per unit time) is proportional to the amount of $\mathrm{ABA}$, i.e the higher the accumulated level of $\mathrm{ABA}$ is, the faster the absolute rate of the $\mathrm{ABA}$ catabolism is, and this further means that the $A B A$ accumulation would, sooner or later, make the rate of $\mathrm{ABA}$ catabolism be rate of $\mathrm{ABA}$ biosynthesis, which will make the $\mathrm{ABA}$ accumulation reach its maximum thus preventing an unlimited accumulation of ABA.

Besides playing important roles in the regulation of stress-induced ABA accumulation in roots, $\mathrm{ABA}$ catabolism may also play crucial roles in the regulation of $\mathrm{ABA}$ transport along the stem. As mentioned above, xylem ABA concentration may be modulated along the stem as a function of its radial transport. The rate of radial transport of ABA is predominantly determined by the ABA concentration gradient between xylem vessel and its surrounding cells (stem parenchyma), and hence, the key point for the modulation of xylem ABA concentration lies in the regulation of this ABA gradient. Supposing that ABA can not be effectively removed in the stem parenchyma surrounding xylem vessel, an equilibrium of the ABA concentration between the xylem vessel and parenchyma will eventually occur, such that the lateral transport of ABA will no longer posses effect on the xylem ABA concentration. In contrast, if the parenchyma ABA can be removed at a rate large enough to support the presence of the radial gradient of ABA concentration, an efflux of ABA from the xylem vessel will always occur during the long-distance transport of the root-sourced ABA, and logically, the longer the root-sourced ABA is transported, the lower the xylem ABA concentration would become. Given the fast rate of ABA catabolism, it is likely that removal of $\mathrm{ABA}$ in the stem parenchyma is predominantly by the ABA catabolism. However, 
whether the rate of this removal is large enough to cause a radial gradient of ABA and whether this radial gradient of ABA is indeed large enough to cause significant decrease in the xylem ABA concentration is not known. The issue about the stomatal sensitivity in relation to the modulation of xylem ABA concentration during its long-distance transport needs to be investigated.

It is well known that for a molecular substance to be a signal, besides having a triggering mechanism it must have a deactivation mechanism. Likely, once the root-sourced ABA enters into leaves it should be removed sooner or later otherwise an unlimited accumulation of ABA would be caused, and this would lead to a permanent inhibition of the stomatal movement even when plants are not stressed. As mentioned above, the absolute rate of ABA catabolism is not only quite fast but also increases proportionally to the accumulated amount of $\mathrm{ABA}$. So, the ABA catabolism should play critical roles in the regulation of $\mathrm{ABA}$ accumulation in leaves thus modulating the stomatal sensitivity to the root sourced $A B A$ signal. The effect of ABA catabolism on the regulation of stomatal movement is complicated. On one hand, the ABA catabolism may play a central role in the removal of ABA thus preventing stomatal movement from permanent inhibition, and on the other hand, the removal of $\mathrm{ABA}$ as a function of the $\mathrm{ABA}$ catabolism may reduce the level of $\mathrm{ABA}$ accumulated in its action sites thus reducing the stomatal sensitivity to the root-sourced ABA signal. The removal of ABA to prevent a permanent inhibition of stomatal movement is clearly not a problem to be concerned, and the major concern is to what an extent the ABA catabolism may be able to modulate the stomatal sensitivity. Regulation of the root to shoot signaling associated with ABA catabolism is an importance issue, which should be paid particular attentions.

\subsection{Modulation of $\mathrm{pH}$ signaling 4.2.1 Effect of chemical compositions in xylem stream}

It is well known that the $\mathrm{pH}$ in solution is determined by a balance among ions and anions, such that a change in the composition of ions or anions may possibly result in a change in $\mathrm{pH}$. More importantly, many transport processes of chemical composition across the cell membrane are associated with $\mathrm{H}^{+}$bumps $\left(\mathrm{H}^{+}\right.$-ATPase), and this must cause a change of $\mathrm{pH}$ in different compartments of the cells. Many ions, such as malate together with other organic acid, nitrate and ammonium are known to be powerful regulators of $\mathrm{pH}$. L-Malate is a prominent organic acid in many plant tissues especially the dicotyledonous plants (Vickery 1963;Buttz and Long 1979), and in monocotyledonous plants transaconitate is the major organic acid with L-malate present in smaller quantities (Clark 1969). Clearly, any changes in the uptake, transport and assimilation of these components may be able to cause a $\mathrm{pH}$ shift.

It has been increasingly suggested that $\mathrm{N}$-containing compounds play crucial roles in the $\mathrm{pH}$ regulation. It was reported that under nitrate nutrition in castor oil plants, the organic acids were present in xylem sap only with trace amounts, and nitrate deprivation considerably increased the amounts of organic acids, thus increasing the $\mathrm{pH}$ from 5.6 to 7.3 (Kirkby and Armstrong 1980). In pepper plants, Dodd et al. (2003) also found that $\mathrm{N}$-deprivation caused an alkalization of xylem sap. It was proposed that when nitrate is plentiful, nitrate will mainly be reduced in leaf cells, but when soil nitrate availability is low the nitrate reduction will be switched from shoot to root (Lips 1997), and this will produce hydroxyl ions, which are then converted to malate, thus leading to an alkalization of xylem sap (Wilkinson and Davies 2002). These observations seem to suggest that the soil drying-induced $\mathrm{pH}$ increase 
in xylem sap is closely related with possible changes in the rate of nitrate reduction in root. Consistent with this hypothesis, there is plenty of evidence demonstrating that soil drying can strongly affect the activity of the nitrate reductase in root, but in contrast, most of the studies demonstrate that soil drying results in a decrease, not an increase in nitrate reductase (Solomonson and Barber 1990). Whether the soil drying-induced $\mathrm{pH}$ increase in the xylem sap is directly governed by nitrate reduction remains to be further investigated.

As mentioned above, many studies demonstrate that soil drying can usually reduce the uptake of nitrate. Theoretically, the reduction in nitrate uptake should give rise to a decrease in the leaf apoplstic $\mathrm{pH}$, and this seems unreasonable, because the reduction of apoplastic $\mathrm{pH}$ would decrease the stomatal sensitivity to ABA. To explain this question, Wilkinson and Davies (2002) proposed that the $\mathrm{N}$ availability may influence the species of the $\mathrm{N}$-containing molecule, and under drought conditions, low nitrate availability would contribute to increases in the content of malate or other organic acid in xylem sap, thus giving rise to a higher apoplastic $\mathrm{pH}$. It should be noted that the soil drying-induced xylem $\mathrm{pH}$ increase and the changes of xylem chemical composition or content may be two different concepts. This is because NO3 -, NH4 + and some other ions have actually no significant effect on xylem $\mathrm{pH}$, but once transported to the leaf they may strongly modify the appolastic $\mathrm{pH}$, and such a viewpoint has been proved by the recent study of Jia and Davies (2007). In regards to $\mathrm{pH}$ signaling in response to soil drying, we should not only pay attention to whether soil drying may directly affect xylem $\mathrm{pH}$, but also pay close attention to whether it may affect the chemical composition or content, and also whether a type of soil may directly affect the chemical composition or content.

\subsubsection{Effect of $\mathrm{H}^{+}$-exchange between xylem vessel and the surrounding cells}

It is known that for the root to shoot signaling of $\mathrm{ABA}$ it is the significant variation in xylem ABA concentration that is predominantly responsible for mediation of stomatal responses to the soil drying stimulus. Likely, for $\mathrm{pH}$ signaling a shift of xylem $\mathrm{pH}$ has been normally thought to be responsible for the mediation of stomatal responses to the soil drying stimulus (Wilkinson 1999). This proposition is actually based on a hypothesis that xylem sap $\mathrm{pH}$ should be approximately the same with that in the apoplastic sap, i.e. the $\mathrm{pH}$ at the action sites of ABA signal. However, it has been increasingly suggested that such a hypothesis is not necessarily correct. Several studies reported that the leaf apoplastic $\mathrm{pH}$ is actually much different from that in xylem sap (Hoffmann and Kosegarten 1995; M“* uhling and Lauchli 2000). Wilkinson and Davies proposed that the climatically induced changes in sap $\mathrm{pH}$ are a result of changes within the leaf apoplast rather than from the incoming xylem sap itself (Wilkinson and Davies 2002). There are also some reports that some factors that affect transpiration (such as high vapour pressure deficit [VPD], photosynthetic photon flux density [PPFD] and temperature) can give rise to a changed $\mathrm{pH}$ in sap expressed from shoot in F. intermedia and H. macrophylla (Wilkinson and Davies 2002). It is not known how the aerial factor can cause the changes in sap pH. It is hypothesized that high VPD may affect leaf cell $\mathrm{H}^{+}$- ATPase activity by causing slight changes in localised water relation, and high PPFD may increase the removal of $\mathrm{CO} 2$ from apopalst, thus causing an apoplastic alkalization (Hartung and Radin 1989; Wilkinson and Davies 2002). Jia and Davies (2007) found that a great $\mathrm{pH}$ gradient exists between the stem base xylem and the leaf vascular system in many plant species. Also, it was found that a change in transpiration rate would be able to cause a change in the leaf xylem sap or apoplastic $\mathrm{pH}$. They provided evidences 
that the great $\mathrm{pH}$ gradient along the stem is a result of $\mathrm{pH}$ modulation by the $\mathrm{H}^{+}$-pump in the vascular parenchyma cells, i.e. the proton in xylem stream can be significantly pumped out thus causing more alkalization with the stem height. Understandably, the removal rate of proton as a function of $\mathrm{H}^{+}$-pump should be affected by sap flow rate, and this may be why transpiration may be able to affect leaf apoplastic $\mathrm{pH}$. Collectively, these data indicate that xylem sap $\mathrm{pH}$ can be strongly modified when passing through plant vascular systems, and moreover, the leaf cells may have a mechanism for the leaf apoplastic $\mathrm{pH}$ to be independently regulated and not necessarily controlled by the level of xylem sap $\mathrm{pH}$.

\section{Coordination of root signals in the regulation of stomatal movement}

$\mathrm{ABA}$ has been thought to be a major signal mediating the stomatal responses to soil drying, but this does not mean that the decreased leaf conductance as a function of the root to shoot signaling is mainly caused by the ABA signals. It has been increasingly suggested that the stomatal regulation upon soil drying is actually controlled by multiple signals, among which ABA is a necessary signal to trigger stomamal closing, but not definitely a signal that is mainly responsible for the decrease of stomatal closure. The key points lie in the synergistic action or coordination among different signals. Detailed discussions above this are given below.

\subsection{Coordination of $\mathrm{ABA}$ and $\mathrm{pH}$ signaling}

Although it has been established that $\mathrm{pH}$ can be a signal mediating the root to shoot signaling, there is evidence that the $\mathrm{pH}$ signal may not be able to independently regulate stomatal movement. A well demonstrated example for this is the research by Wilkinson et al. (1998). Using tomato mutant as the research material, Wilkinson et al. found that soil drying resulted in an increase in xylem sap $\mathrm{pH}$ from 5.0 to 8.0, but when artificial xylem sap buffered to different $\mathrm{pH}$ was fed to the detached leaves of either wild type or ABA-deficient mutant flacca, it was found that the wild type but not flacca leaves exhibited reduced transpiration rates with the increase of $\mathrm{pH}$. On the other hand, a well watered concentration of ABA added in the sap, just like the wild type flacca was able to exhibit a transpirational reduction with $\mathrm{pH}$ increased from 6.25 to 7.75 . These data demonstrated that the stomatal regulation by xylem $\mathrm{pH}$ absolutely requires the presence of $\mathrm{ABA}$.

It has been proposed that the coordination between the $\mathrm{pH}$ and $\mathrm{ABA}$ signaling is based on the effect of $\mathrm{pH}$-regulation of $\mathrm{ABA}$ accumulation at its action sites, i.e. soil drying-induced $\mathrm{pH}$ increase in xylem would make apoplast of the leaf more alkaline, which would contribute to a sequestration of more ABA in the apoplast of guard cells, thus promoting the stomatal closure in the presence of ABA (Wilkinson 1999; Wilkinson and Davies 2002). However, owing to the modulation of xylem $\mathrm{pH}$ along the stem as described above, the soil drying-induced shift in the xylem $\mathrm{pH}$ may not necessarily lead to a variation in the leaf apoplastic $\mathrm{pH}$ that is big enough to pose an effect on the ABA accumulation. In addition, it should be noted that the pattern of this modulation may vary greatly among different plant species or under different culture conditions. For example, while soil drying is able to increase the $\mathrm{pH}$ of xylem sap in tomato, Commelina communis and barley, it has no effect on the $\mathrm{pH}$ of xylem sap in Hydrangea macrophylla cv Bluewave and Cotinus coggyria cv Royal Purple, and in Forsythia intermedia cv Lynwood it can even lead to a decrease in the $\mathrm{pH}$ (Wilkinson and Davies 2002). As mentioned above, stomatal sensitivity to root ABA signal 
often varies greatly with plant species or plant culture conditions. It is not known whether this variation may be correlated to the big difference in patterns of $\mathrm{pH}$ variation among different plant species or culture conditions.

Besides functioning to modulate ABA accumulation within leaves, $\mathrm{pH}$ may also play a role in the modulation of the ABA signal intensity. A well demonstrated example for this is a recent research carried out by $\mathrm{Li}$ et al (2010). Using grapevine (Vitis riparia $\times$ Vitis labrusca) as the research plant, they found that the intensity of ABA signal (i.e. xylem ABA concentration) increased rather than decreased as commonly thought during the longdistance transport of the root-sourced ABA, and in the mean while, they also found that there existed a basipetal $\mathrm{pH}$ gradient along the stem. The basipetal $\mathrm{pH}$ gradient along the stem may be related to the different activity of $\mathrm{H}^{+}$-ATPase in the parenchyma of the vascular bundle. No matter mechanism for the presence of the basipetal $\mathrm{pH}$ gradient, this study has provided strong evidences that the enforced ABA signal along stem is a result of $\mathrm{pH}$ modulation, i.e. the increased $\mathrm{pH}$ towards the apex contributed to reduce the rate of $\mathrm{ABA}$ efflux from the xylem vessel. Collectively, the result of this study indicated that the intensity of the root-sourced ABA signal can be modulated by $\mathrm{pH}$ along its long-distance transmission in the stem.

The coordination of the $\mathrm{ABA}$ and $\mathrm{pH}$ signaling has complicated the shoot to shoot signaling. The reason for this is that $\mathrm{pH}$ itself can be modulated by many factors. Logically, any $\mathrm{pH}$ regulator may have a possibility to pose an effect on the regulation of the root to shoot signaling. A well demonstrated example for this is the effect of nitrate nutrition on the modulation of $\mathrm{pH}$ signaling as well as the stomatal sensitivity to the root ABA signal. Kosegarten et al. (1999) found that nitrate nutrition could cause a high apoplastic $\mathrm{pH}$ in immature sunflower leaves, but they were not able to observe such a phenomenon in mature leaves or in immature leaves with sole $\mathrm{NH}^{+}$or $\mathrm{NH}^{4}+/ \mathrm{NO}^{3}$-as nutrition. M* uhling and Lauchli (2001) also found that nitrate nutrition caused more alkaline leaf apoplastic sap than ammonium nutrition, in both Phaseolus vulgaris and sunflower, but not in Vicia faba or Zea mays. More recently, using a $\mathrm{pH}$ ratio imaging technique, Jia and Davies (2007) clearly showed that feeding $\mathrm{NO}^{3}$ - induced a significant alkalization of the leaf apoplast, while the feeding of $\mathrm{NH}^{4}+$ had a contrary effect (i.e. it gave rise to a significant reduction of the apoplastic $\mathrm{pH}$ in Commelina communis). Importantly, feeding $\mathrm{NH}^{4}+$ or $\mathrm{NO}^{3}$ - significantly decreased (for $\mathrm{NH}^{4+}$ ) or increased (for $\mathrm{NO}^{3-)}$ the stomatal responses to $\mathrm{ABA}$, suggesting that the $\mathrm{pH}$-regulator is indeed able to modulate stomatal sensitivity.

\subsection{Hydraulic signal}

A major issue about the chemical signaling is its argument with a hydraulic signaling. While numerous studies have strongly demonstrated the important roles of the chemical signaling in the root to shoot communication, are also plenty of evidences supporting the potential roles of the hydraulic signaling in the root to shoot signaling (Petersen et al. 1991; Saliendra et al. 1995; Fuchs and Livingston 1996; Yao et al. 2001; Comstock 2002; Sperry et al. 2002). In studies emphasizing the hydraulic regulation of stomatal behavior, it is even thought that a lack of response to shoot water potential would be potentially fatal to plants (Comstock 2002). For example, in Douglas fir Fuchs and Livingston (1996) found that the reduction in leaf conductance as a result of soil drying could be progressively reversed by the pressurization of the root system, and furthermore, once the pressurization was released the 
leaf conductance would return to its prepressurization levels within minutes, strongly indicating that the hydraulic signal was a predominant regulator of the stomatal behavior. Similar findings were made by Saliendra et al. (1995) in woody plants Betula occidentalis and Yao et al. (2001) in bell pepper (Capsicum annuum L. vau. Maor). Recently, using ABAdeficient mutant of Arabidopsis and a noninvasive imaging system for ABA action in combination with grafting technique, Christmann et al. (2007) have provided strong evidences that the stomatal behavior is controlled by a hydraulic signal rather than rootsourced ABA signal.

Although it is difficult to clearly address the debate between the chemical and hydraulic signaling, it seems that the three points below may contribute to understanding some of the key points about this debate. The first is the big difference in the stomatal behaviors among different species, i.e. while a change in xylem ABA concentration can greatly regulate stomatal movement in some plant species, it may have no effects on the stomatal movement in other plant species. The second is that even for a specific plant species different experimental condition and design may possibly give rise to different results. For example, the developmental stage, the size, the root to shoot ratio and so on all contribute to affect the stomatal behavior and the water relationship of whole plant. Additionally, the nature of soil may also likely pose an effect on the $\mathrm{pH}$ signaling as discussed above, thus modulating the stomatal sensitivity. Thirdly, the lack of a unitive and identical description for the stomatal behavior may possibly affect the assessment on the nature of signals. For example, to describe the stomatal responses to soil drying, the phrase 'stomatal closure' was commonly used in published reports. Actually, a mild drought can only, to some degree, cause a decrease in the stomatal conductance but not a stomatal closure. Given that the decreased degree of the stomatal conductance is correlated to the nature of the signals, a different evaluation of the stomatal closure would be likely to affect the determination of the root to shoot signals. No matter what reason for the different conclusions drawn in different researches, it seems that these two theories don't actually conflict with each other, i.e. different theories may be applicable to different cases depending on plant species, developmental stages or even their culture conditions.

According to the basic theory on the water transport in plants, the decreased water availability of roots as a result of soil drying would inevitably lead to a decrease in the leaf water potential, and this would again inevitably cause a decrease in the stomatal conductance. Therefore, irrespective of evidences for the chemical signaling, the hydraulic signal must play crucial roles in regulation of stomatal movement in response to soil drying. The key point lies in that to what a degree the chemical signaling may be able to control the stomatal behavior and at what sage of the soil drying the hydraulic signaling starts to play a role in the regulation of the stomatal movement. Additionally, much attention should be paid on the practical significance of the two different kinds of signaling in the water-saving agriculture not just on their relative importance in the stomatal regulation. The practical significance of the chemical signaling is embodied in its potential roles in reducing the transpiration without negative impacts on the food production. Although a mild decrease in the leaf water potential may affect, to some extent, plant biomass, it may not significantly affect the food production as a function of the changed assimilate transport and allocation. However, a mild decrease in the leaf water potential may be able to strongly induce stomatal closing, thus may also significantly improve WUE. In this context, it is the cooperation of the two different kinds of signaling that may play a maximum positive role 
in the water saving agriculture. Interestingly, there is evidence that a mild decrease in leaf water potential could increase the stomatal sensitivity to ABA. For example, in a research by Tardieu et al., epidermal pieces of Commelina communis were incubated in media with different water potential adjusted by polyethylene glycol. In the media without ABA, the water potentials between -0.3 and -1.5 megapascals had no significant effect on stomatal aperture, however, when ABA was added to the media with a decrease of the water potential from -0.3 to -1.5 megapascals, the stomatal aperture significantly decreased, which strongly suggested that the stomatal sensitivity to ABA could be modified by water potential (Tardieu et al., 1992). The same observation was obtained by feeding ABA into the field grown plants. There is evidence that the two kinds of signaling may be able to interact with each other and jointly control the stomatal behavior.lants over different ranges of leaf water potential (Tardieu and Davies 1993). These studies suggest that the hydraulic signaling may function to strengthen the chemcial signaling, thereby jointly regulating the stomatal responses to soil drying. For a given plant species, It is of high importance to quantitatively determine the critical point of the decrease in leaf water potential, at which a maximum increase in WUE can be achieved.

\section{Manipulation of the systematic signaling in water saving agriculture}

\subsection{Exploitation of the systematic signaling to increase water use efficiency}

Food production is at the cost of water resources. With the fast reduction of the limited water resources, the only way for the development of a sustainable agriculture is to increase the water use efficiency (WUE). The practical significance of the systemic chemical signaling lies in its effective regulation of the transpiration without a strongly negative impact on the food production, and hence, exploitation of the systemic chemical signaling is a good strategy to increase WUE. As described above, systemic signaling is embodied in that, in responses to a stimulus in one part of the plant, the corresponding responses may take place in another part of the plant. Therefore, for an exploitation of the root to shoot signaling to increase the WUE, we need to manipulate water deficit appropriately. The spilt-root experiment is known to be a good demonstration of the root to shoot signaling. Such an idea can be adopted in practical agriculture. Based on the theory of the systemic signaling, two water-saving irrigation techniques have been developed and widely used in many sectors of the agriculture in many counties, one commonly used technique is the regulated deficit irrigation (RDI) and another is the partial rootzone drying (PRD) (Loveys, 1991; Loveys et al., 2004; Dodd et al., 2006; Fereres and Soriano, 2007; Sadras, 2009).

RDI works on the premise that a mild water deficit would greatly reduce plant transpiration while it does not significantly affect the food production as a result of improved harvest index, such that an improvement of WUE would be achieved. However, in practice a sublimate control of the water deficit is difficult to be realized, and it is more likely that RDI would give rise to a great decrease in biomass, thus significantly reducing crop yield. RDI may be successfully used in the production of some horticulture plants, such as tomato and some fruit trees, where a vigorous vegetative growth may not be needed and even adverse to fruit production (Davies et al., 2001). In comparison with RDI, PRD is easier to be appropriately manipulated in practice and more widely used in water-saving agriculture. PRD works on the principle that when part of the root system is 
allowed to dry and the remaining roots are kept well-watered, the drying roots would trigger chemical signaling by which transpiration can be reduced, and meanwhile, the food production may be not affected as a function of the maintaining of a relatively high leaf water status by the wet roots (Dodd et al., 2006; Dry et. al., 2001; Wilkinson and Hartung 2009). PRD techniques can be adapted to the use of either drip or furrow irrigation and a commonly adopted method is alternative irrigation in crop production (Costa et al., 2007; Kang et al., 2000).

A major issue about the chemical signaling is its capability to regulate stomatal behavior, and additionally this capability often varies greatly among different plant species and different circumstances. In particular, it appears that chemical signaling plays little roles in most of woody plants (Comstock 2002, Ren et al., 2007). Therefore, trying to increase the stomatal sensitivity to the root chemical signals is a major concern for a better use of PRD. The stomatal sensitivity may be modulated by many factors as noted above. However, for a given plant species, a practical strategy may be $\mathrm{pH}$ modulation. Modulation of $\mathrm{pH}$ may be achieved by an appropriate manipulation of fertilizing, but until now, no much information is available about how PRD can be improved by an appropriate manipulation of fertilizing. More importantly, it should be noted that the water-saving effect of PRD may be not accounted for solely by the chemical signaling because the possibility of the involvement of hydraulic signaling can not be excluded in this process. PRD technique is based on a hypothesis that wet part of the root system is able to keep leaf water potential relatively constant as the remaining part of the root system dries. Under the field conditions, however, this may be not allays the case as expected. Whether a decrease in leaf water potential occurs should depend on the balance between water loss and income of the lamia. This balance can be affected by many factors not just by stotmtal movement, such as air temperature, humidity, shoot/root ratio, water conductance of roots and so on. A change in any of these factors may contribute to breaking the balance, and thus, posing an effect on the leaf water potential, .e.g. dry and hot whether may possibly give rise to a significant decrease in the leaf eater potential especially for those plants with a low root/shoot ratio even if the plants are kept well-watered. Given the potential roles of hydraulic signaling in the stomatal regulation, more attentions should be paid on the ratio of the dry/wet roots in RPD, so that degree of the water deficit should be finely controlled to the critical point at which a maximum decrease in the stomatal conductance, and in the mean time, a minimum negative impact on the food production can be achieved. In this context, it is the coordination of the chemical and hydraulic signaling that functions to effectively save water during the implement of PRD technique.

\subsection{Exploitation of the systematic signaling to increase fruit quality.}

As mentioned above, the systemic chemical signaling seems to be a good theory that can be exploited to save water in practical agriculture production. However, the water-saving capability of chemical signaling may be very limited for many plant species or under many developmental stages especially for woody plants. To effectively save water, PRD should be appropriately manipulated so that a coordination of the chemical and hydraulic signaling functions to induce a relatively maximum reduction in the stomatal conductance. Effectively saving water would inevitably pose negative impact on plant growth and development, and this would greatly limit the use of PRD technique for many crop plants. It seems that saving water is always contradictory to food production. Excitingly, this can be well resolved in the 
case of fruit production in many sectors of agriculture. In china, for example, no matter in cultivated areas or yield, the apple production is the first in the world, however its apple market only shares less than $5 \%$ in the world. The major reason for this is its poor quality. In many sectors, it is the fruit quality but not yield that has become a factor limiting the development of fruit industry.

Application of RDI and PRD inevitably reduces vegetative growth and this will again pose negative impacts on crop yield. Unlike the crop yield, fruit quality is less negatively affected by vegetative growth, and by contrast, vigorous vegetative growth may be adverse to fruit quality even to the yield as a result of assimilate competition. Additionally, light intensity is known to be a predominant factor in the regulation of fruit quality and a reduction in vegetative growth may contribute to reducing the canopy density hence resulting in better light penetration to the bunch zone (Davies et al., 2001; Dry et al., 1996). More importantly, it has been well established that mild water deficit would be able to increase sugar content of fruits, which is a major index of the fruit quality. Further more, it is worth noting that most arid agricultural land is in developing countries, where the economic income is a major concern for the local farmers. Increasing fruit quality will greatly increase the farmers' economic income, and this will surely save land and water to grow more crop plants for an expected economic income to be achieved. In this context, application of RDI and RPD in fruit production is of more significance than in crop plants as regards to their water-saving effects. In Australia and many other counties, RDI and PRD techniques have been successfully used for many years to save water and improve fruit quality in grape production (Dry et al., 1996; Davies et al., 2002). Collectively, while there are many arguments and concerns about the application of RDI and PRD techniques with an aim to effectively improve WUE of many crop plants, the application of the two techniques seems to be a perfect strategy for the production of fruit trees.

\section{Acknowledgment}

This work is supported by grants from National Crops Transgenic Special Grant (2009ZX08009-0738 and 2009ZX08003-009B) and the National Natural Science Foundation (31171921)

\section{References}

Auge RM, Stodola AJW, Ebel RC, Duan X (1995) Leaf elongation and water relations of mycorrhizal sorghum in response to partial soil drying: two Glomus species at varying phosphorus fertilization. J. Exp. Bot. 46, 297-307.

Blackman PG, Davies WJ (1985) Root to shoot communication in maize plants of the effects of soil drying. J. Exp. Bot. 36, 39-48.

Buttz RG, Long RC (1979) L-Malate as an essential component of the xylem fluid of corn seedling roots. Plant Physiol. 64, 684-689.

Clark RB (1969) Organic acids from leaves of several crop plants by gas chromatography. Crop Sci. 9, 341-343.

Comstock JP (2002) Hydraulic and chemical signaling in the control of stomatal conductance and transpiration. J. Exp. Bot. 53, 195- 200. 
Comstock J, Mencuccini M (1998) Control of stomatal conductance by leaf water potential in Hymenoclea salsola (T. \& G.), a desert subshrub. Plant Cell Environ. 21, 1029-1038.

Creelman RA, Gage DA, Stults JT, Zeevaart JAD (1987) Abscisic acid biosynthesis in leaves and roots of Xanthium strumarium. Plant Physiol. 85, 726-732.

Davies WJ, Zhang J (1991) Root signals and the regulation of growth and development of plants in drying soil. Annu. Rev. Plant Physiol. Plant Mol. Biol. 42, 55-76.

Davies WJ, Tardieu F, Trejo CL (1994) How do chemical Signal work in plants that grow in drying soil? Plant Physiol. 104, 309-314.

Dodd IC, Tan LP, He J (2003) Do increases in xylem sap pH and/or ABA concentration mediate stomatal closure following nitrate deprivation? J. Exp. Bot. 54, 1281-1288.

Else MA, Davies WJ, Whitford PN, Hall KC, Jackson MB (1994) Concentrations of abscisic acid and other solutes in xylem sap from root systems of tomato and castor-oil plants are affected by the method of sap collection. J. Exp. Bot. 45, 317-323.

Else MA, Hall KC, Arnold GM, Davies WJ, Jackson MB (1995) Export of abscisic acid, 1aminocyclopropane-1-carboxylic acid, phosphate, and nitrate from roots to shoots of flooded tomato plants. Plant Physiol. 107, 377-384.

Fawzi A, Razem, Luo M, Liu JH, Abrams SR, Hill RD (2004) Purification and characterization of a Barley Aleurone abscisic acidbinding protein. J. Biol. Chem. 279, 9922-9929.

Fuchs EE, Livingston NJ (1996) Hydraulic control of stomatal conductance in Doughlas fir and alder seedlings. Plant Cell Environ. 19,1091-1098.

Gollan T, Passioura JB, Munns R (1986) Soil water status affects the stomatal conductance of fully turgid wheat and sunflower plants.Aust. J. Plant Physiol. 13, 459-464.

Gollan T, Schurr U, Schulze ED (1992) Stomatal response to drying soil in relation to changes in the xylem sap composition of Helianthus annuus. I. The concentration of cations, anions, amino acids in, and $\mathrm{pH}$ of, the xylem sap. Plant Cell Environ. 15, 551-559.

Gowing DJ, Davies WJ, Jones HG (1990) A positive root sourced signal as an indicator of soil drying in apple, Malus x domestica Borkh. J. Exp. Bot. 41, 1535-1540.

Gowing DJG, Jones HG, Davies WJ (1993) Xylem-delivered abscisic acid: the relative importance of its mass and its concentration in the control of stomatal aperture. Plant Cell Environ. 16, 453-459.

Hartung W, Radin JW (1989) Abscisic acid in the mesophyll apoplast and in the root xylem sap of water-stressed plants: the significance of $\mathrm{pH}$ gradients. Curr. Topics Plant Biochem. Physiol. 8, 110- 124.

Hartung W, Radin JW, Hendrix DL (1988) Abscisic acid movement into the apoplastic solution of water-stressed cotton leaves: Role of apoplastic pH. Plant Physiol. 86, 908-913.

Hartung W, Sauter A, Hose E (2002) Abscisic acid in the xylem: where does it come from, where does it go to? J. Exp. Bot. 53, 27-32.

Hoffmann B, Kosegarten H (1995) FITC-dextran for measuring apoplast $\mathrm{pH}$ and apoplastic $\mathrm{pH}$ gradients between various cell types in sunflower leaves. Physiol. Plant. 95, 327335.

Hornberg C, Weiler EW (1984) High affinity binding sites for abscisic acid on the plasmalemma of Vicia faba guard cells. Nature 310, 321-324. 
Holbrook NM, Shashidhar VR, James RA, Munns R (2002) Stomatal control in tomato with ABA-deficient response of grafted plants to soil drying. J. Exp. Bot. 53, 1503-1514.

Jackson MB (1993) Are plant hormones involved in root to shoot communication? Adv. Bot. Res. 19, 103-187.

Jia WS, Zhang J (1997) Comparison of exportation and metabolism of xylem-delivered ABA in maize leaves at different water status and xylem sap pH. Plant Growth Regul. 21, 43-49.

Jia WS, Zhang JH (1999) Stomatal closure is induced rather by prevailing xylem abscisic acid than by accumulated amount of xylemderived abscisic acid. Physiol. Plant. 106, 268275.

Jia WS, Davies WJ (2007) Modification of leaf apoplastic $\mathrm{pH}$ in relation to stomatal sensitivity to root-sourced abscisic acid signals. Plant Physiol. 143, 68-77.

Jia WS, Zhang J, Zhang DP (1996) Metabolism of xylem-delivered ABA in relation to ABA flux and concentration in leaves of maize and Commelina communis L. J. Exp. Bot. 47, 1085-1091.

Jones RJ, Mansfield TA (1970) Suppression of stomatal opening in leaves treated with abscisic acid. J. Exp. Bot. 21, 714-719.

Kaiser WM, Hartung W (1981) Uptake and release of abscisic acid by isolated photoautotrophic mesophyll cells, depending on $\mathrm{pH}$ gradients. Plant Physiol. 68, 202-206.

Khalil AAM, Grace J (1993) Does xylem ABA control the stomatal behaviour of waterstressed sycamore (Acer pseudoplatanus L.) seedlings? J. Exp. Bot. 44, 1127-1134.

Kirkby EA, Armstrong MJ (1980) Nitrate uptake by roots as regulated by nitrate assimilation in the shoot of castor oil plants. Plant Physiol. 65, 286-290.

Kosegarten HU, Hoffmann B, Mengel K (1999) Apoplastic $\mathrm{pH}$ and $\mathrm{Fe}_{3+}$ reduction in intact sunflower leaves. Plant Physiol. 121, 1069-1079.

Li Y, Walton DC (1987) Xanthophylls and abscisic acid biosynthesis in water-stressed bean leaves. Plant Physiol. 85, 910-915.

Lips SH (1997) The role of inorganic nitrogen ions in plant adaptation processes. Russ. J. Plant Physiol. 44, 421-431.

Loveys BR(1991) What use is a knowledge of ABA physiology for crop improvement? In: Davies WJ, Jones HG, eds. Abscisic acid, Oxford: Bios Scientific Publishers, 245-259.

Loewenstein NJ, Pallardy SG (1998) Drought tolerance, xylem sap abscisic acid and stomatal conductance during soil drying: a comparison of canopy trees of three temperate deciduous angiosperms. Tree Physiol. 18, 431-439.

Munns R, Cramer GR (1996) Is coordination of leaf and root growth mediated by abscisic acid? Opin. Plant Soil 185, 33-49.

Munns R, Passioura JB, Milborrow BV, James RA, Close TJ (1993) Stored xylem sap from wheat and barley contains a transpiration inhibitor with a large molecular size. Plant Cell Environ. 16, 867-872.

M* uhling KH, Lauchli A (2000) Light-induced $\mathrm{pH}$ and $\mathrm{K}_{+}$changes inthe apoplast of intact leaves. Planta 212, 9-15.

M“ uhling KH, Lauchli A (2001) Influence of chemical form and concentration of nitrogen on apoplastic $\mathrm{pH}$ of leaves. J. Plant Nutr. 24,399-411. 
Norman SM, Maier VP, Pon DL (1990) Abscisic acid accumulationand carotenoid and chlorophyll content in relation to water stress and leaf age of different types of citrus. J. Agric. Food Chem. 38, 1326-1334.

Parry AD, Horgan R (1991) Carotenoids and abscisic acid biosynthesis in higher plants. Physiol. Plant. 82, 320-326.

Parry AD, Babiano MJ, Horgan R (1990) The role of ciscarotenoids in abscisic acid biosynthesis. Planta 182, 118-128.

Passioura JB (1987) The use of the pressure chamber for continuously monitoring and controlling the pressure in the xylem sap of the shoot of intact transpiring plants. $\mathrm{Zn}$ Proceedings of the International Conference on Measurement of Soil and Plant Water Status. University Press, Logan. pp. 31-34.

Passioura JB (1980) The transport of water from soil to shoot in wheat seedlings. J. Exp. Bot. 31, 333-345.

Passioura JB (1988) Water transport in and to roots. Annu. Rev. Plant Physiol. Plant Mol. Biol. 39, 245-265.

Passioura JB, Tanner CB (1985) Oscillations in apparent hydraulic conductance of cotton plants. Aust. J. Plant Physiol. 12, 455-461.

Petersen KL, Moreshet S, FuchsM(1991) Stomatal responses of field grown cotton to radiation and soil moisture. Agron. J. 83, 1059-1065.

Qin XQ, Zeevaart JAD (1999) The 9-cis-epoxycarotenoid cleavage reaction is the key regulatory step of abscisic acid biosynthesis in water-stressed bean. Proc. Natl Acad. Sci. 96, 15 354- 15361.

Ren HB, Gao ZH, Chen L, Wei KF, Liu J,Fan YJ, William J Davies, WS Jia and JH Zhang (2007) Dynamic analysis of ABA accumulation in relation to therate of ABA catabolism in maize tissues under water deficit. J. Exp. Bot. 58, 211-219.

Saliendra NZ, Sperry JS, Comstock JP (1995) Influence of leaf water status on stomatal response to humidity, hydraulic conductance, and soil drought in Betula occidentalis. Planta 196, 357- 366.

Sauter A, Hartung W (2002) The contribution of internode and mesocotyl tissues to root-toshoot signaling of abscisic acid. J. Exp. Bot.53, 297-302.

Sauter A, Davies WJ, Hartung W (2001) The long-distance abscisic acid signal in the droughted plant: the fate of the hormone on its way from root to shoot. J. Exp. Bot. Special Issue, 52, 1991-1997.

Schulze ED (1991) Water and nutrient interactions with plant water stress. In: Mooney HA, Winner WE, Pell EJ, eds. Response of Plants to Multiple Stresses Academic Press, New York, pp. 89- 103.

Schumaker KS, Sze H (1987) Decrease of $\mathrm{pH}$ gradients in tonoplast vesicles by $\mathrm{NO}_{3}$ and $\mathrm{Cl}$ : Evidence for $\mathrm{H}_{+}-$coupled anion. Transp.Plant Physiol. 83, 490-496.

Schwartz SH, Tan BC, Gage DA, Zeevaart JAD, McCarty DR (1997) Specific oxidative cleavage of carotenoids by Vp14 of maize. Science 276, 1872-1874.

Seo M, Koshiba T (2002) Complex regulation of ABA biosynthesis in plants. Trends Plant Sci. $7,41-48$.

Slovik S, Hartung W (1992a) Compartmental distribution and redistribution of abscisic acid in intact leaves. II. Model analysis. Planta 187, 26-36.

Slovik S, Hartung W (1992b) Compartmental distribution and redistribution of abscisic acid in intact leaves. III. Analysis of the stress signal chain. Planta 187, 37-47. 
Solomonson LP, Barber MJ (1990) Assimilatory nitrate reductase: Functional properties and regulation. Annu. Rev. Plant Physiol. Plant Mol. Biol. 4, 225-253.

Sperry JS, Hacke UG, Oren R, Comstock JP (2002) Water deficits and hydraulic limits to leaf water supply. Plant Cell Environ. 25, 251- 263.

Tardieu F, Davies WJ (1993) Integration of hydraulic and chemical signaling in the control of stomatal conductance and water status of droughted plants. Plant Cell Environ. 16, 341-349.

Tardieu F, Zhang J, Davies WJ (1992) What information s conveyed by an ABA signal from maize roots in drying field soil? Plant Cell Environ. 15, 185-191.

Trejo C, Clephan AL, Davies WJ (1995) How do stomata read abscisic acid signals? Plant Physiol. 109, 803-811.

van Beusichem ML, Baas R, Kirkby EA, Nelemans JA (1985) Intracellular pH regulation during $\mathrm{NO}_{3-}$ assimilation in shoot and roots of Ricinus communis. Plant Physiol. 78, 768-773.

Vickery HB (1963) Metabolism of the organic acids of tobacco leaves. XIX. Effect of culture of excised leaves in solutions of potassium glutamate. J. Biol. Chem. 238, 2453-2459.

Wright STC (1977) The relationship between leaf water potential and levels of abscisic acid and ethylene in excised wheat leaves. Planta 134, 183-189.

Wilkinson S (1999) pH as a stress signal. Plant Growth Regul. 29, 87-99

Wilkinson S, Davies WJ (1997) Xylem sap pH increase: a drought signal received at the apoplastic face of the guard cell that involves the suppression of saturable abscisic acid uptake by the epidermal symplast. Plant Physiol. 113, 559-573.

Wilkinson S, Davies WJ (2002) ABA-based chemical signaling: the co-ordination of responses to stress in plants. Plant Cell Environ. 25, 195-210.

Wilkinson S, Corlett JE, Oger L, Davies WJ (1998) Effects of xylem pH on transpiration from wild-type and flacca tomato leaves: a vital role for abscisic acid in preventing excessive water loss even from well-watered plants. Plant Physiol. 117, 703-709.

Yao C, Moreshet S, Aloni B (2001) Water relations and hydraulic control of stomatal behavior in bell pepper plant in partial soil drying. Plant Cell Envrion. 24, 227-235.

Zeevaart JAD (1980) Changes in the levels of abscisic acid and its metabolites in excised leaf blades of Xanthium strumarium during and after water stress. Plant Physiol. 66, 672-678.

Zeevaart JAD (1983) Metabolism of abscisic acid and its regulation in Xanthium leaves during and after water stress. Plant Physiol. 71, 477-481.

Zeevaart JAD, Creelman RA (1988) Metabolism and physiology of abscisic acid. Annu. Rev. Plant Physiol. Plant Mol. Biol. 39, 439-473.

Zhang J, Davies WJ (1989) Abscisic acid produced in dehydrating roots may enable the plant to measure the water status of the soil. Plant Cell Environ. 12, 73-81.

Zhang J, Davies WJ (1990) Changes in the concentration of ABA in xylem sap as a function of changing soil water status com account for changes in leaf conductance and growth. Plant Cell Environ. 13, 271-285.

Zhang J, Davies WJ (1991) Antitranspirant activity in the xylem sap of maize plants. J. Exp. Bot. 42, 317-321.

Zhang J, Jia W (1997) Effects of water status and xylem pH on metabolism of xylem transported abscisic acid. Plant Growth Regul.21, 51-58. 
Zhang J, Jia W, Zhang DP (1997) Re-export and metabolism of xylemdelivered ABA in attached maize leaves under different transpirational fluxes and xylem ABA concentration. J. Exp. Bot. 48, 1557- 1564.

Zhu X, Zhang J (1997) Anti-transpiration and anti-growth activities in the xylem sap from plants under different types of soil stress. New Phytol. 137, 657-664. 


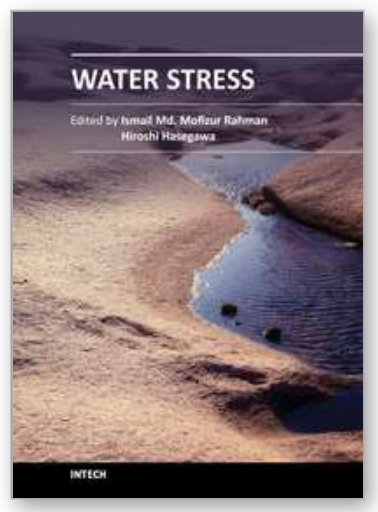

\author{
Water Stress \\ Edited by Prof. Ismail Md. Mofizur Rahman
}

ISBN 978-953-307-963-9

Hard cover, 300 pages

Publisher InTech

Published online 25, January, 2012

Published in print edition January, 2012

Plants experience water stress either when the water supply to their roots becomes limiting, or when the transpiration rate becomes intense. Water stress is primarily caused by a water deficit, such as a drought or high soil salinity. Each year, water stress on arable plants in different parts of the world disrupts agriculture and food supply with the final consequence: famine. Hence, the ability to withstand such stress is of immense economic importance. Plants try to adapt to the stress conditions with an array of biochemical and physiological interventions. This multi-authored edited compilation puts forth an all-inclusive picture on the mechanism and adaptation aspects of water stress. The prime objective of the book is to deliver a thoughtful mixture of viewpoints which will be useful to workers in all areas of plant sciences. We trust that the material covered in this book will be valuable in building strategies to counter water stress in plants.

\title{
How to reference
}

In order to correctly reference this scholarly work, feel free to copy and paste the following:

Bingbing Li and Wensuo Jia (2012). Systemic Signaling Under Water Deficit Condition and Its Exploitation in Water Saving Agriculture, Water Stress, Prof. Ismail Md. Mofizur Rahman (Ed.), ISBN: 978-953-307-963-9, InTech, Available from: http://www.intechopen.com/books/water-stress/systemic-signaling-under-water-deficitcondition-and-its-exploitation-in-water-saving-agriculture

\section{INTECH}

open science | open minds

\author{
InTech Europe \\ University Campus STeP Ri \\ Slavka Krautzeka 83/A \\ 51000 Rijeka, Croatia \\ Phone: +385 (51) 770447 \\ Fax: +385 (51) 686166 \\ www.intechopen.com
}

\author{
InTech China \\ Unit 405, Office Block, Hotel Equatorial Shanghai \\ No.65, Yan An Road (West), Shanghai, 200040, China \\ 中国上海市延安西路65号上海国际贵都大饭店办公楼 405 单元 \\ Phone: +86-21-62489820 \\ Fax: $+86-21-62489821$
}


(C) 2012 The Author(s). Licensee IntechOpen. This is an open access article distributed under the terms of the Creative Commons Attribution 3.0 License, which permits unrestricted use, distribution, and reproduction in any medium, provided the original work is properly cited. 